\title{
The Four Scaffolding Modules for Collaborative Problem-Based Learning through the Computer Network on Moodle LMS for the Computer Programming Course
}

\author{
Monchai Tiantong ${ }^{1} \&$ Sanit Teemuangsai ${ }^{2}$ \\ ${ }^{1}$ Faculty of Technical Education, KMUTNB, Bangkok, Thailand \\ ${ }^{2}$ Faculty of Education, Rajabhat Maha Sarakham University, Maha Sarakham, Thailand \\ Correspondence: Monchai Tiantong, Faculty of Technical Education, King Mongkut's University of Technology \\ North Bangkok, 1518 Pracharat 1 Road, Bangsue, Bangkok 10800, Thailand. Tel: 662-555-2000. E-mail: \\ monchai@kmutnb.ac.th
}

Received: February 20, 2013 Accepted: March 13, $2013 \quad$ Online Published: April 26, 2013

doi:10.5539/ies.v6n5p47

URL: http://dx.doi.org/10.5539/ies.v6n5p47

\begin{abstract}
Scaffolding is a learning approach designed to promote a deeper understanding, it is the support given during the learning process which is tailored to the needs of the student with the intention of helping the student achieve the learning goals, including resources, a compelling task, templates and guides, and guidance on the development of cognitive and social skills. Meanwhile, problem-based learning (PBL) situate learning in complex tasks. Such task require scaffolding to help students engage in sense making, managing their investigations, problem-solving processes, and encouraging students to articulate their thinking and reflect on their learning. This study aimed to develop four scaffolding modules for collaborative problem-based learning through the computer network on Moodle LMS for the computer programming course of undergraduate students, and to analyze the satisfaction of the experts and students after using the developed scaffolding modules. The four scaffolding modules consisted of metacognitive scaffolding, conceptual scaffolding, strategic scaffolding, and procedural scaffolding, each of which represented by a 3-D animation expert cartoon to attract students. The sample group were twenty-two students of small group pilot and six experts. The findings indicated that the degree of satisfaction towards the scaffolding from the experts was high and the degree of the satisfaction towards the scaffolding from the students was also high. This can be used the four scaffolding modules to complete PBL task successfully.
\end{abstract}

Keyword: scaffolding, Moodle LMS, delphi technique, ADDIE instructional model

\section{Introduction}

\subsection{Using Scaffolding in Learning}

In the globalization period, everything changes so fast in all aspects such as economics, politics, societies, technology, culture. The world becomes a learning society in which knowledge and intelligence become important instruments in boosting up the potentials and development of the country. Education has become the core to push the whole country securely to the next century, but the quality of the education needs to be constantly revised. Studying directly from teachers through memorizing and focusing only the contents cannot develop students completely (Satayasai, 2004). Thus, children and young people have not yet been developed to their full potentials and have not been cultivated with the desired characteristics such as curiosity, analysis thinking, logical solution, disciplines and honesty. Moreover, teachers usually give lectures focusing on the contents and the subjects, but not the students. This kind of teaching cannot make students learn to face problems and be able to solve them in their real lives (The Office of the National Education Committee, 2002). Good teaching and learning needs to be able to draw students' attention, serve different groups of students, and emphasize more on skill practice, thinking process and situational management.

Problem-based learning is an effective instructional approach used to enrich students to become better problem solvers for today's information technology society. An essential characteristic of PBL is the use of a problem to focus and hold learning. PBL emphasizes active knowledge building while students solve problems rather than exposing them to discipline knowledge before problem solving (Albanese \& Mitchell, 1993; Hmelo \& Evensen, 2000). This approach uses problems to start the learning process, develop the reasonable problem-solving skills 
and search for relevant information for solving those problems. The PBL success depends on the students' practice and the unknown problems. When students face the problems, they may be discouraged to solve them and learn something from that. Teachers need to give necessary skills to motivate and guide students, as well as acknowledge them about a lot of sources of information (Howard \& Robyn, 1980). This technique is called scaffolding, it is an assistant approach to help students solve problems by themselves or achieve their goals. Students also learn from working with adults and friends and develop more knowledge and competence or intelligence to finally be able to solve problems. Scaffolding shapes the way students interact in a PBL environment by imposing additional structure to their learning (Ge \& Land, 2004), moreover scaffolding can decrease the flexibility of PBL and may reduce student opportunity to do exploratory learning, which may have a negative effect on learning in a PBL environment (Pea, 2004). In education, scaffolding can be thought of as three related pedagogical scales. First, there is the meaning of providing a support structure to enable certain activities and skills to develop. Second, there is the actual carrying out of particular activities in class. And, third, there is the assistance provided in moment-to-moment interaction. Schematically, this can be represented in the following way: a) scaffolding I: planned curriculum progression over time (e.g. a series of tasks over time, a project, a classroom ritual), b) scaffolding II: the procedures used in a particular activity (an instantiation of scaffolding I), and c) scaffolding III: the collaborative process of interaction (the process of achieving scaffolding II) (Walqui, 2006).

There are actually five different scaffoldings: 1) modeling of desired behaviors, 2) offering explanations, 3) inviting student participation, 4) verifying and clarifying student understandings, and 5) inviting students to contribute clues (Hogan and Pressley, 1997). These techniques may either be integrated or used individually, depending on the material being taught. The instructor's goal in employing scaffolding techniques is offering just enough assistance to guide the students toward independence and self-regulation. However, Hannafin and Oliver (1999) divides scaffolding into four different categories as follows: 1) metacognitive scaffolding, it suggests how to deal with thoughts during the learning in the self-thinking process, 2) conceptual scaffolding, it helps learners to build concepts about what they have learned, recognize the concept of knowledge relating to the problems, gain structure of what to do and separate it into the categories of concept, 3) strategic scaffolding, it promotes analysis, planning, decision-making during the study, separation method and choice of information used to connect previous knowledge to new experience. Strategies then motivate learners to be aware of the instruments and sources that may be useful under the particular circumstance, and 4) procedural scaffolding, it suggests how to use sources and instruments, as well as advise the learners during the learning to use intelligence tools (Hannafin, \& Oliver, 1999).

In term of conceptual scaffolding, they will mainly benefit students' understanding towards content knowledge instead of overall problem-solving performance (Jonassen, 1986; Cho \& Jonassen, 2002). On the other hand, they may reduce students' cognitive load spent on content learning, therefore, they may have more cognitive resources to manage the problem-solving process. In a study of scaffoldings by Cho and Jonassen (2002), students participated in an online discussion board to discuss and solve problems in groups. A conceptual scaffolding was designed to help them post well-structured argumentation. Results indicated that students who received the scaffolding produced better quality argumentation, more claims, and more problem-oriented communication during discussion than those who did not have the scaffolding. In a follow-up individual problem-solving activity, students from the scaffolding group created significantly higher quality argumentation than those in the no scaffolding group (Cho \& Jonassen, 2002). However, scaffolding-supported students did not outperform no-scaffolding students on problem-solving performance. Meanwhile, Su and Klein (2010), investigated the use of scaffoldings in problem-based hypermedia by three hundred and twelve undergraduate students enrolled in a computer literacy course worked in project teams to use a problem-based, hypermedia program focused on designing a personal computer. The program included conceptual scaffoldings, metacognitive scaffoldings, or no scaffolding. The results revealed that posttest scores for students who received conceptual scaffoldings were significantly higher than those who received metacognitive scaffoldings (Su \& Klein, 2010). Type of scaffoldings also had a significant impact on student attitudes. Findings have implications for the design and delivery of problem-based hypermedia. Conceptual scaffoldings can direct student attention to important information and encourage understanding, and a study by Wolf (2000) investigated the effects of a metacognitive scaffoldings on students' problem solving performance and attitudes in an online multimedia resource database. The results showed that students who received using scaffoldings in problem-based hypermedia, the scaffoldings achieved significantly higher score on problem-solving performance than their peers who didn't receive the scaffoldings. However, no significant difference was found on student attitudes between two conditions (Wolf, 2000). 
With the right techniques and materials, a teacher can provide the temporary support that children need to grow intellectually. These scaffoldings allow children to reach levels of understanding and task mastery that would have been unattainable without it. Just as scaffoldings help workers to complete difficult jobs, learning scaffolding helps children to build solid understandings of challenging tasks or problems, particularly in problem-based learning that is more likely to motivate and excite the students to learn, wherein they need to play an active role in analyzing things for a given assignment, it enhances the problem solving skills of the students as opposed to providing only theoretical knowledge. Learning, therefore, goes beyond bookish knowledge and helps the students face and see through practical problems (Buzzle, 2000), and also allowing the students to use prior knowledge to solve a new problem, it ensures deeper understanding, moreover it cultivates independence, curiosity, skills for self-directed, and life-long learning. According to researches, learning is enhanced when new information is presented through a meaningful context and comes in conflict with the existing knowledge.

Basically, in term of modern technology, nobody can deny that technology has revolutionized education. Educators have also dramatically adjusted their teaching methods in response to new technology over the years. Gone are the field of dreams days when believing that simply putting computers in the classroom would automatically make a difference (Smith \& Winthrop, 2012). The potential of technology to help improve education has significance beyond teaching children reading and math. Quality education plays an important role in promoting economic development, improving health and nutrition and reducing maternal and infant mortality rates. Economic growth, for example, can be directly impacted by the quality of the education systems in developing countries. Many schools now carefully consider cost and application when debating how to best use new technology. Because technology changes rapidly and affects learning and teaching and brings the learning society to everyone. Technology then has been applied to develop the quality of learning and teaching. Since the computer network works faster and more efficient, it becomes the useful instrument in developing and supporting the learning and teaching process. This is also a good time for learners to take advantage of the network. At present, they do not need to study only from the textbook in classes, but they can learn more from other sources of information. The varieties and communities of learning help expand education opportunities and equalities more than ever before. There is, however, a certain challenge to develop the learning and teaching through the network, that is, giving more opportunities to learners to learn from interactive communication without staying together at the same time or in the same place. They can communicate their ideas and learn from each other with various supportive instruments, thus reducing the limitations of time, place and participants.

Although the learning network appears to bring several advantages, some learners still face learning problems, for example, they fail to cooperate because learners in the same group pay less attention to the study. Some learners may not be sure nor be interested in participating in activities or may have negative attitudes to the learning network, resulting in unsuccessful learning and teaching. Therefore, ways to solve these problems are: organizing suitable learning environment, developing better teaching techniques, increasing potentials and using suitable and efficient supporting technology.

In term of the collaborative problem-based learning model as shown in Figure 1. It was developed by Teemuangsai \& Tiantong (2008), this model was obtained from the opinion survey of the experts using the delphi technique. The model consists of eight modules as shown in Figure 1, as follows: 1) PBL module, this is the main part of the model that provides problems or situation to the students, 2) student module, this connects to PBL, knowledge, collaborative, scaffolding, and assessment module, 3) collaborative module, this provides collaborative learning techniques for group learning, 4) communication module, this provides communication tools for group learning, 5) knowledge module, this provides an effective information for students to complete their tasks, 6) coaching module, this module coaches the students as a reviewer, director, monitor, facilitator, and evaluator, 7) assessment module, this is to evaluate the learning progression of the student, and 8) scaffolding module, this is designed to promote a deeper learning for students (Teemuangsai, \& Tiantong, 2008). 


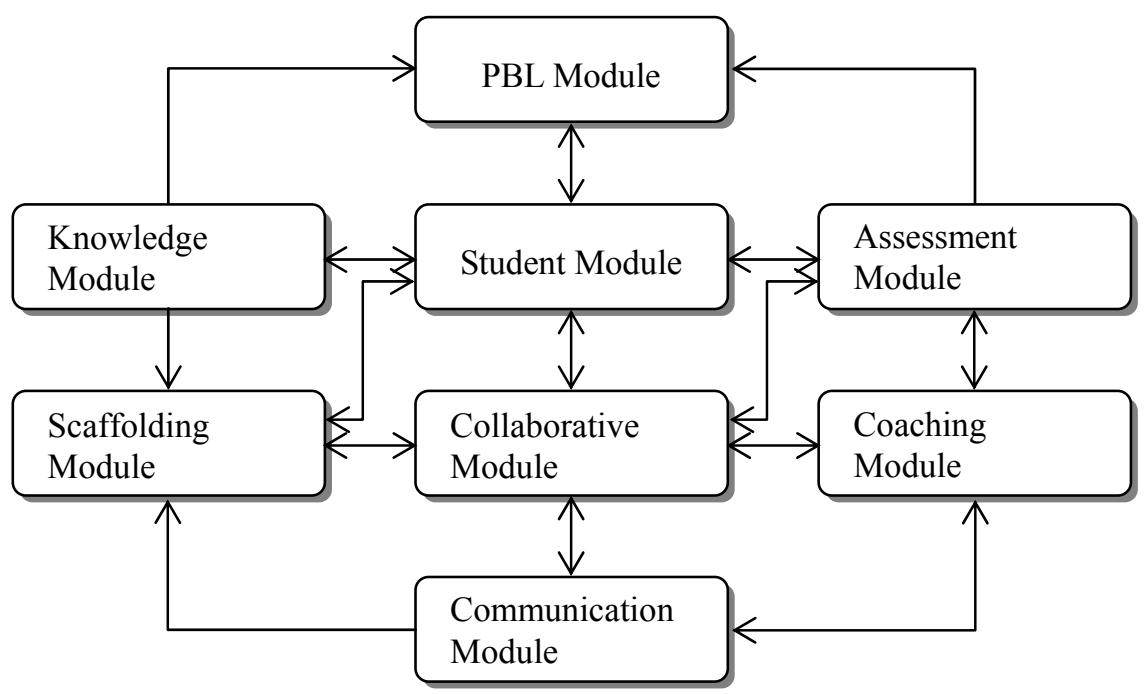

Figure 1. Components of the collaborative problem-based learning model by Delphi technique

Because of such problems above, the authors were interested in studying and developing the scaffolding to promote learning through the computer network in the computer programming course for undergraduate student. Later, the problem-based scaffolding modules would be associated with the collaborative learning model and learned through the computer network developed by the authors. Thus, this study aims to develop four scaffolding modules for collaborative problem-based learning through the computer network on Moodle LMS for the computer programming course.

\section{Method}

\subsection{Main Procedure}

The research procedure followed the five phases of the ADDIE instructional model (Clark, 2004) as follows: 1) A - Analysis: to begin, study of the previous research about the scaffolding in learning and teaching, write the course curriculum and assign the target learners, 2) D - Design: the next step was to design the contents structure, topics and lessons, learning activities and evaluation criteria, sources, and scaffolding techniques, 3) D Development: in this stage, the researchers applied the Moodle LMS to develop the lessons and added activities, quizzes, tests, learning sources, portfolios, communications, scaffolding, follow-up and evaluation, 4) I Implementation: this step was to assign learners into small groups, set up location, and train learners for the tryout lessons, and 5) E - Evaluation : students and experts were asked to evaluate the lessons. The test results would represent the satisfaction towards the developed scaffolding modules in the computer programming course.

\subsection{Analysis, and Design Phase}

Actually this phase consists of the system requirements and the process requirements. The system requirements describe the students needs in terms of the system or the scaffolding modules that are created, meanwhile the process requirements describes how students interact with the modules. Ten experts with at least five years experiences at university level were used in this phase to analyze these requirements of the system using focus group discussion.

\subsection{Development Phase}

The four scaffolding modules were developed through the Moodle LMS on the computer network. This phase elaborates and builds on the system requirements and the process requirements that were produced in the analysis and design phase.

\subsection{Implementation Phase}

This phase is where the scaffolding modules for collaborative problem-based learning through the computer network on Moodle LMS for the computer programming course are actually delivered to the samples for evaluation. 


\subsection{Evaluation Phase}

The total of eighty-one undergraduate students in the Computer Science program, Faculty of Science and Technology, Rajabhat Maha Sarakham University were used, Simple random sampling was also used to select only twenty-two students from this group to be the samples of the study for the learning computer programming course with the Moodle LMS.

Six experts, with at least five years experience at university level were separated into two groups, a technical group and procedural group to evaluate the satisfaction towards the developed scaffolding

\section{Results}

\subsection{The four Scaffolding Modules}

The four scaffolding modules for collaborative problem-based learning through the computer network on Moodle LMS for the computer programming course are shown in Figure 2.

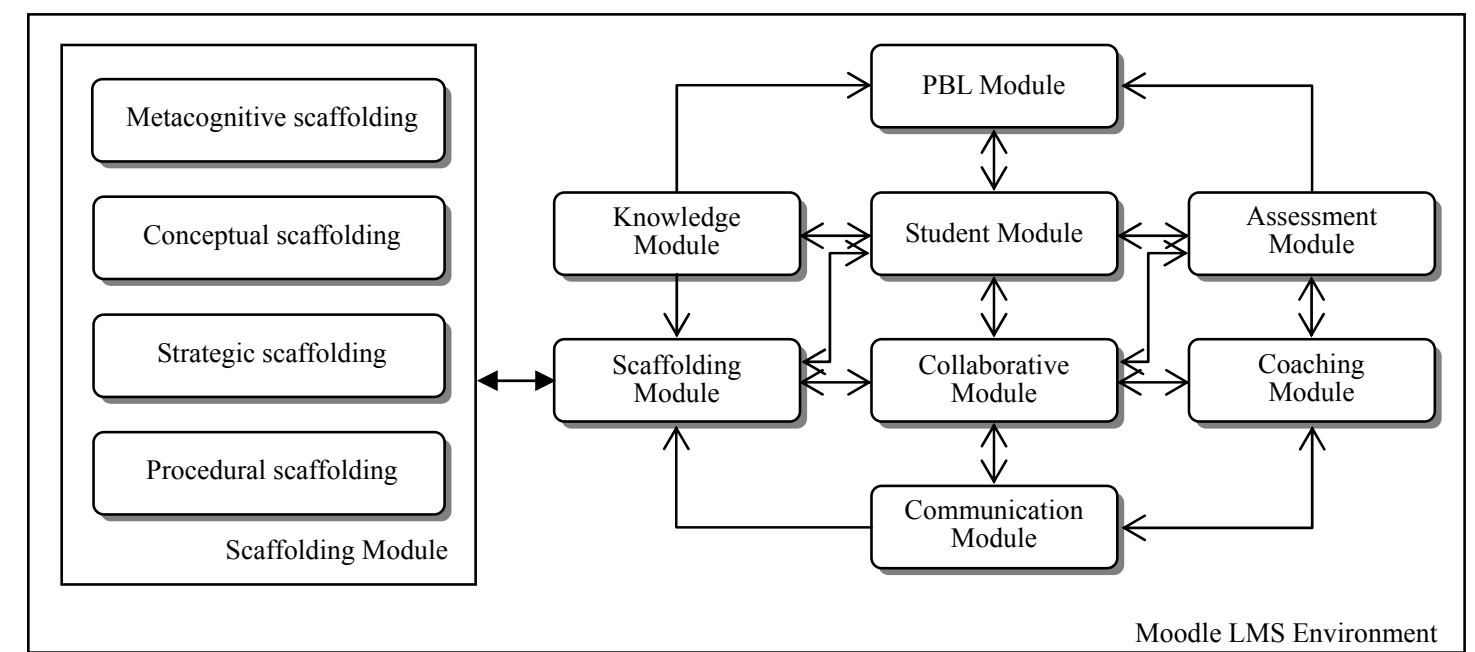

Figure 2. The four scaffolding modules for collaborative problem-based learning through the computer network on Moodle LMS for the computer programming course

The four scaffolding modules consisted of metacognitive scaffolding, conceptual scaffolding, strategic scaffolding, and procedural scaffolding, each of which represented by a 3-D animation experts cartoon to attract students as follows: a) Uncle E, he represents the metacognitive module specialized in giving concepts and using logics and problem structure to fight for solutions. (metacognitive scaffolding), 2) Dr.W, he represents the conceptual module specialized in thinking, finding ways to solutions and solving puzzles and problem games. (conceptual scaffolding), 3) Professor $\mathrm{H}$, he represents the strategic module specialized in giving advice and will power, solving group conflicts, providing learning techniques and additional sources. (strategic scaffolding), and 4) Miss J, she represents the procedural module specialized in giving advice and examples of the problem-based learning process. (procedural scaffolding), as shown in Figure 3. 


\begin{tabular}{|l|l|} 
He represents the metacognitive module specialized in giving \\
concepts and using logics and problem structure to fight for \\
solutions. \\
(Metacognitive scaffolding)
\end{tabular}

Figure 3. 3-D animation experts cartoon of the four scaffolding modules

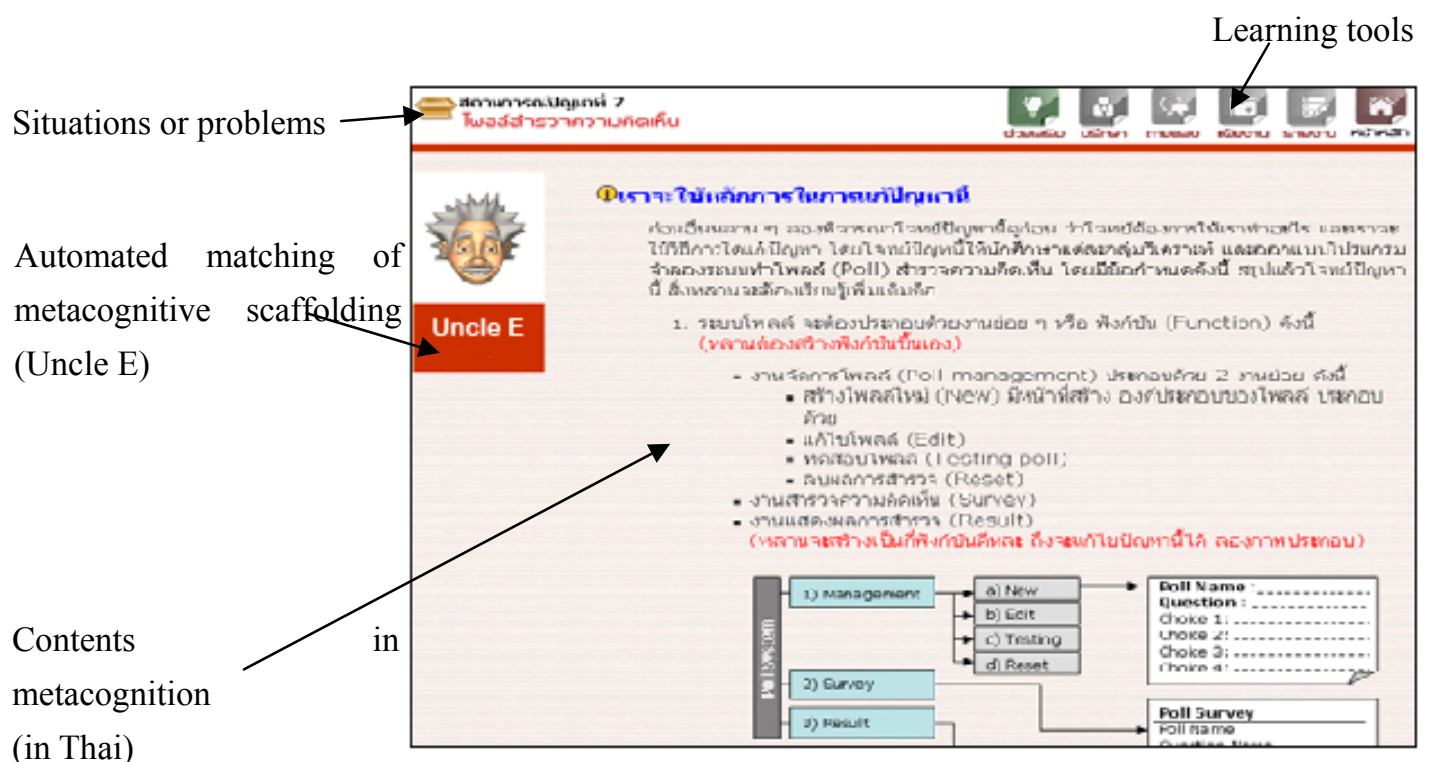

Figure 4 (a). Example of learning screen (in Thai) for student automated to scaffoldings 


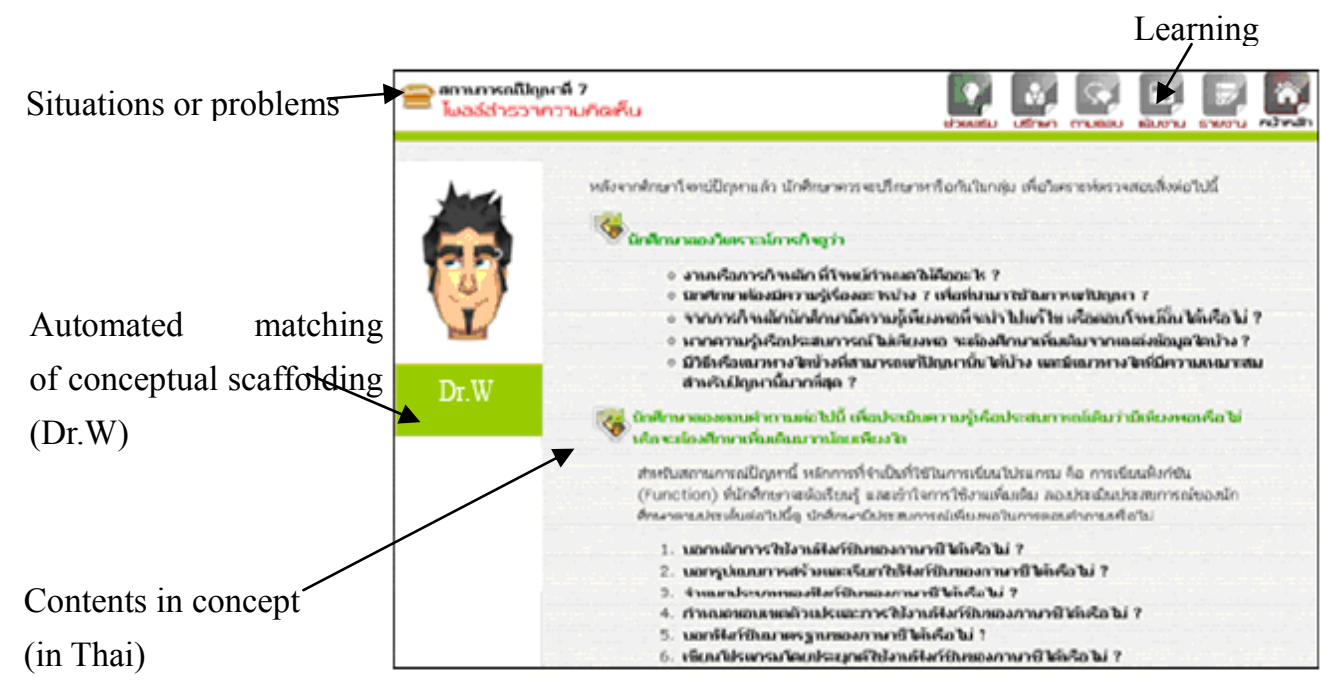

Figure 4 (b). Example of learning screen (in Thai) for student automated to scaffoldings

In figure 4 (a) \& 4 (b), it shows a sample of content-based scaffoldings for students. The four scaffoldings is automated to match the content type of the lessons, as Uncle $\mathrm{E}$ is automated to match the metacognitive content, Dr.W is automated to match the concept content, Professor H. is automated to match the strategic content, and Miss $\mathrm{J}$ is automated to match the procedural content. These approaches provides students with confidence in their own learning. This is the main goal of scaffolding, enabling students to become more independent and a self-regulating learner with problem solving skills (Hartman, 2002).

\subsection{The Evaluation Results of the Four Scaffolding Modules}

The students and experts were asked to evaluate the lessons using a rating-scale questionnaire. The results represent the satisfaction towards the developed scaffolding modules in computer programming course for undergraduate student in Rajabhat Maha Sarakham University, as follows:

1) The experts expressed very high levels of satisfaction.

2) The sample students also expressed high levels of satisfaction.

\section{Conclusion and Discussion}

Scaffolding is often considered as a part of the cognitive apprenticeship theory, this theory addresses the problem of coaching a student to perform a specific task. A student learns through active participation in a task in an authentic setting in a close collaboration with a master (Pahl, 2002), meanwhile scaffolding is suitable for active learning. The teacher can be replaced by an intelligent agent that also controls the learner activity. Activity theory is a framework that can help us to redefine scaffolding in the context of the computer network. Activity theory is a conceptual framework that can describe the structure, development, and context of computer-supported activities (Nardi 1997). Its emphasis on the interaction between agents and their environments explains the principle of tool mediation. Tools shape the way humans interact with reality. Tools reflect experiences other people, such as the master in the apprenticeship approach. This experience is accumulated in structural and behavioral properties of the tool. A teaching and learning environment is the tool that provides a student with access to a part of the reality, the course subject guided by structural and behavioral rules defined by the instructor. Approaches such as problem-based learning, constructivism, or exploratory learning can be derived from constructivist theory (Dede 1995). Constructivism says that knowledge is constructed by a student, rather than taught to the student. The process of knowledge construction is viewed as deeper than the traditional approach. The student is engaged in solving meaningful problems. This lends itself to be supported by scaffolding.

Problem-based learning is the instructional approach in which carefully constructed, open-ended problems are used by groups of students to work through content to a solution, has gained in many segments of higher education. Research shows that PBL gives the learner greater long-term benefits than traditional learning, and many successful and progressive universities around the world use it in their courses. Graduates of PBL courses advance faster and further in their careers. It can also provide students with insights into the learning process. It encourages students to learn through the structured exploration of a research problem and to take responsibility for their own learning by providing a problem that needs solving. The fundamental basis of engaging learners 
with a problem is that they develop skills necessary to solve the problem, therefore it can and has been used as a method of teaching the practical application of knowledge in a real world setting (Dennen, 2004). In term of benefits of PBL are as i.e., it makes learning more student centered, experiential and activity based as it engages students in structuring solutions to real life, relevant, contextualized problems. Therefore students become actively engaged in meaningful learning, it promotes student interaction and teamwork, thereby enhancing interpersonal skills, working with group dynamics, peer evaluation encouraging an appreciation of teamwork and the value of others and how to present and defend their ideas, and students can achieve higher levels of comprehension and skill development as PBL focuses on activities rather than knowledge, encouraging deeper rather than surface learning (Bridge \& Hallinger, 1991).

However, every PBL project is carefully designed by experts or teachers to expose to the information and skills that want students to learn. When assigned a project, the designers are give a statement of the problems, questions to consider when solving the problem, a framework for the time and effort students should spend on the project, and support from the courses, peers, tutorials, and teachers, that is the role of scaffolding to support students as they work on a specific task (NIU, 2008). Because one of the main benefits of scaffolding is that it provide for a supportive learning environment. Teachers are caring and interested in helping students learn. Students are free to ask questions, provide feedback, and support their peers in learning new material, teachers who use scaffolding become more of a mentor and facilitator of knowledge than the dominant content expert. This teaching style provides the incentive for students to take a more active role in their own learning, moreover students share the responsibility of teaching and learning through scaffoldings that require them to move beyond their current skill and knowledge levels. Through this interaction, students are able to take ownership of the learning event (Hogan, 1997). Therefore, the need to use a scaffolding will occur when teacher realize a student is not progressing on some aspect of a task or unable to understand a particular concept. Although scaffolding is often carried out between the teacher and one student, scaffoldings can successfully be used for classroom and online learning through the computer network.

Thus, this study intended to develop four scaffolding modules for collaborative problem-based learning through the computer network on Moodle LMS in the computer programming course, and to study the satisfaction of the experts and students towards the four scaffolding models. The participants of this study were six technical and procedural experts and twenty-two students. The results suggest the four scaffolding modules: metacognitive, conceptual, strategic and procedural ones. The modules were represented by 3-D animation pictures to draw students' attention and recognition. Instead of using messages, the pictures of the experts were used to communicate with students. The evaluation of the experts' satisfaction was at a very appropriate level of satisfaction and that of the students was also at a high level of satisfaction. In conclusion, Moodle LMS is ready-made with no extra costs, it is suitable for students to use as an instrument in designing the online lessons which are highly flexible and efficient with ease of use of Moodle LMS enabling regular updating of links/materials. Teacher could edit/add new links in lessons, immediately as they are suggested by students, to provide an ordered list of course requirements (Couteur, 2007), and finally, the designers or teachers could create scaffolding in lessons to complete students' situations or problems successfully.

For further study, the authors would like to compare the learning achievements of the control group and the experimental group who learn with and without the developed scaffoldings modules.

\section{References}

Albanese, M. A., \& Mitchell, S. (1993). Problem-based learning: A review of literature on its outcomes and $\begin{array}{llll}\text { implementation } & \text { issues. }\end{array}$ http://dx.doi.org/10.1097/00001888-199301000-00012

Bridges, E. M., \& Hallinger, P. (1991). Problem based learning in medical managerial education. Paper presented for the Cognition and School Leadership Conference of the National Center for educational Leadership and the Ontario Institute for Studies in Education. Nashville, TN.

Buzzle. (2000). Problem-based Learning. Retrieved May 1, 2010, from http://www.buzzle.com/articles/problem -based-learning.html

Cho, K., \& Jonassen, D. H. (2002). The effects of argumentation scaffolds on argumentation and problem solving. Educational Technology Research and Development, 50(3), 5-22. http://dx.doi.org/10.1007/BF02505022

Clark, D. (2004). History of knowledge, ISD, learning, and management. Retrieved June 8, 2011, from http://www.skagitwatershed.org/ donclark/history_isd/addie.html 
Couteur, L. R. (2007). Computer in the classroom, King Edward VI Grammar School. Chelmsford, Essex, England.

Dede, C. (1995). The evolution of constructivist learning environments: Immersion in distributed, virtual worlds. Educational Technology, 35(5), 46-52.

Dennen, V. P. (2004). Cognitive apprenticeship in educational practice: Research on scaffolding, modeling, mentoring, and coaching as instructional strategies. In D. H. Jonassen (Ed.), Handbook of Research on Educational Communications and Technology (2nd ed., p. 815). Mahwah, NJ: Lawrence Erlbaum Associates.

Ge, X., \& Land, S. M. (2004). A conceptual framework for scaffolding ill-structured problem-solving processes using question prompts and peer interactions. Educational Technology Research and Development, 52(2), 5-22. http://dx.doi.org/10.1007/BF02504836

Hannafin, M., Land, S., \& Oliver, K. (1999). Open ended learning environments: foundations, methods, and models. In C. Reigeluth (Ed.), Instructional Design Theories and Models (Vol. II). Mahway, NJ: Erlbaum.

Hartman, H. (2002). Scaffolding \& Cooperative Learning. Human Learning and Instruction (pp. 23-69). New York: City College of City University of New York.

Hmelo, C. E., \& Evensen, D. H. (2000). Problem-based learning: Gaining insights on learning interactions through multiple methods of inquiry. In D. Evensen, \& C. Hmelo (Eds.), Problem-based learning: a research perspective on learning interactions (pp.1-16). Mahwah, NJ: Lawrence Erlbaum Associates.

Hogan, K., \& Pressley, M. (1997). Scaffolding Student Learning: Instructional Approaches \& Issues. Brookline Books, Inc.: Cambridge, M.A.

Howard, B., \& Robyn, T. (1980). Problem-based Learning: An approach to medical education. New York: Springer Publishing Company.

Jonassen, D. H. (1986). Hypertext principles for text and courseware design. Educational Psychologist, 21(4), 269-292. http://dx.doi.org/10.1207/s15326985ep2104_3

Nardi, B. (Eds.). (1997). Educational Context and Consciousness: Activity Theory and Human-Computer Interaction. MIT Press.

NIU. (2008). Instructional Scaffolding to Improve Learning, Northern Illinois University. Retrieved June 12, 2012, from http://www.niu.edu/taconnections/2008/fall/scaffolding.shtml

Pahl, C. (2002). An Evaluation of Scaffolding for Virtual Interactive Tutorials. In M. Driscoll, \& T. Reeves (Eds.), Proceedings of World Conference on E-Learning in Corporate, Government, Healthcare, and Higher Education 2002 (pp. 740-746). Chesapeake, VA: AACE.

Pea, R. D. (2004). The social and technological dimensions of scaffolding and related theoretical concepts for learning, education, and human activity. Journal of the Learning Sciences, 13, 423-451. http://dx.doi.org/10.1207/s15327809j1s1303_6

Satayasai, W. (2004). Problem-based Learning, the Student-Centered Learning Model. Bangkok: BookNet.

Smith, M., \& Wintrop, R. (2012). A New Face of Education: Bringing Technology into the Classroom in the Development World. Brooke Shearer Working Paper Series, January 2012.

$\mathrm{Su}$, Y., \& Klein, J. (2010). Using Scaffolds in Problem-based Hypermedia. Journal of Educational Multimedia and Hypermedia, 19(3), 327-347.

Teemuangsai, T., \& Tiantong, M. (2008). The Collaborative Problem-Based Learning Model through the Computer Network. Proceedings of the 4th National Conference on Computer and Information Technology (May 23-24, 2008), King Mongkut's University of Technology North Bangkok, Bangkok, Thailand, 179-182.

The Office of the National Education Committee. (2002). The National Education Plan (2002-2016). Bangkok, Thailand.

Walqui, A. (2006). Scaffolding instruction for English learners: A conceptual framework. International Journal of Bilingual Education and Bilingualism, 9(2). http://dx.doi.org/10.1080/13670050608668639

Wolf, S. E. (2000). The Big Six Information Skills as a metacognitive scaffold in solving information-based problems. Unpublished doctoral dissertation, Arizona State University, Tempe, Arizona. 